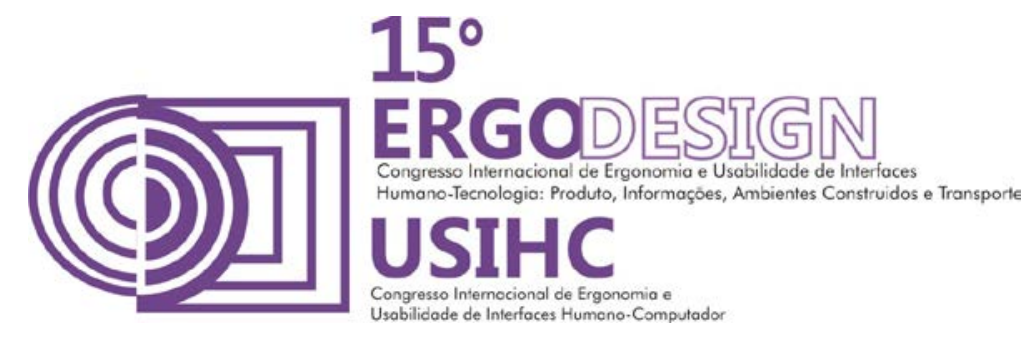

\title{
TESTE DE USABILIDADE DA REVISTA DE MOLDES DE COSTURA BURDASTYLE
}

\section{USABILITY TEST OF THE SEWING PATTERN MAGAZINE BURDASTYLE}

\author{
PERITO, Renata Zandomenico (1); \\ DEMILIS, Marcelo Pereira (2); \\ KOWALSKI, Eduardo Peixoto (3); \\ REIS, Alexandre Amorim (4) \\ FERREIRA, Marcelo Gitirana Gomes (5);
}

(1) UDESC, Bach.

e-mail: reperito@gmail.com

(2) UDESC, Bach.

e-mail: marcelodemilis@gmail.com

(3) UDESC, Bach.

e-mail: eduardokowalski@gmail.com

(4) UDESC, D.Sc.

e-mail: alexandre.reis@pq.cnpq.br

(5) UDESC, D.Sc.

e-mail: marcelo.ferreira@udesc.br

\begin{abstract}
RESUMO
Este artigo apresenta o teste de usabilidade da revista BurdaStyle, e objetiva verificar se esta pode ser usada por iniciantes. Foram realizados testes em laboratório com 12 participantes sem conhecimento de costura, que executaram três tarefas que simulam a realidade de uso do produto. Foram colhidos dados quantitativos, e qualitativos. Concluiu-se que a revista apresenta obstáculos para os iniciantes, como a presença de termos especializados, a falta de explicações claras e a grande quantidade de informação em uma mesma folha de moldes.
\end{abstract}

Palavras-chave: design, usabilidade, moldes de costura, revista 


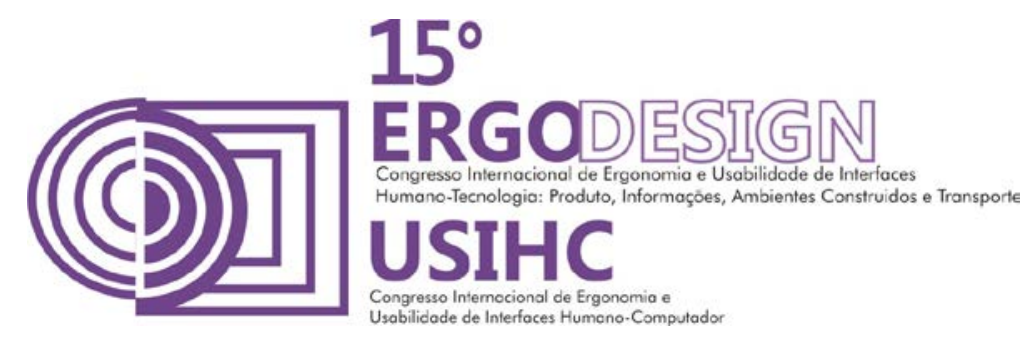

\begin{abstract}
This article presents the usability test of the magazine BurdaStyle, and aims to verify if beginners can use it. Laboratory tests were made with 12 participants with no sewing knowledge, and they went through three tasks that simulated the reality of use of the product. Quantitative and qualitative data were collected. Results show that the magazine presents barriers to beginners, such as use of specialised terms, lack of clear explanation, and large quantity of information in the same pattern sheet.
\end{abstract}

Keywords: design, usability, sewing patterns, magazine

\title{
1. INTRODUÇÃO
}

As revistas de moldes de costura são, desde o século XIX, uma das maneiras mais econômicas para as costureiras, donas de casa ou leigos de conseguir moldes de costura.

Antes do advento dos moldes prontos e baratos, segundo estudo de Kidwell (1979), para que uma mulher cortasse uma roupa que servisse bem e estivesse de acordo com a tendência da época, havia duas opções: ou ela era uma experiente costureira e conhecia as técnicas complicadas e precisas de corte, ou ela copiava os moldes de uma roupa pronta.

No século XIX, surgiram vários sistemas de corte de roupas, alguns complicados e voltados aos profissionais, e outros mais simples, direcionados principalmente a donas de casa. Dentre esses mais simples estão os moldes prontos cortados em papel. (KIDWELL, 1979)

A maior revista de moldes de costura mundial atualmente é a BurdaStyle, vendida em mais de 90 países e publicada em 28 línguas diferentes. A revista foi criada por Aenne Burda em 1950 na Alemanha com a intenção de tornar as tendências de moda mais acessíveis às mulheres. (DEUTSCHE WELLE, 2009)

Manequim foi a primeira revista de moldes de costura lançada no Brasil, em 1959. Publicada ainda hoje, estima um público de um milhão de leitores e imprime 202 mil exemplares ao mês. A editora divulga que $83 \%$ dos leitores são das classes B e C. (EDITORA ABRIL, 2014)

Apesar de serem voltadas tanto a mulheres experientes em costura quanto a iniciantes, as revistas de molde atuais parecem complicadas à primeira vista. Considerando a popularidade das revistas de molde tanto no Brasil quanto no exterior, mostrou-se interessante testar seu uso com iniciantes. Para este teste, foi escolhida a revista BurdaStyle devido à sua abrangência.

Com este estudo, almeja-se obter dados que ajudarão a torná-las mais fáceis de usar por iniciantes ao diminuir o número de erros e o tempo para executar as tarefas. Buscou-se responder às seguintes perguntas:

- Quão fácil é encontrar as informações necessária sobre um modelo?

- Quão fácil é encontrar o molde desejado na folha de moldes?

- Os usuários conseguem transferir o tamanho desejado?

- Os usuários conseguem copiar todas as marcações pertinentes ao molde desejado?

- O material de ajuda é suficiente para auxiliar o usuário a completar as tarefas? 


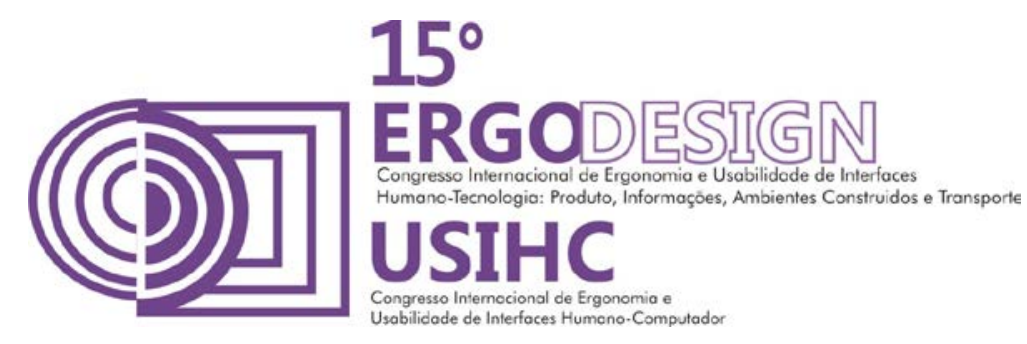

- Que obstáculos os usuários encontram ao tentar executar as tarefas?

- Que comentários fazem ao tentar executar as tarefas?

\section{MÉTODO}

Usabilidade é definida pela ISO 9241 (ABNT) como "medida em que um sistema, produto ou serviço pode ser usado por usuários específicos para se atingir objetivos específicos com eficácia, eficiência e satisfação em um determinado contexto de uso." A usabilidade pode ser testada com usuários em qualquer fase do projeto, tanto para testar conceitos quanto para coletar dados de performance de produtos em estágios mais avançados de desenvolvimento. (NEMETH, 2004)

Neste estudo, a usabilidade da revista BurdaStyle foi testada em laboratório como um teste somativo. Testes de usabilidade somativos são conduzidos nas fases comple de criação de um produto, quanto a estrutura já foi definida. O objetivo é verificar se o usuário consegue completar tarefas definidas e identificar problemas de usabilidade. (RUBIN; CHISNELL, 2008)

Este foi um teste de usabilidade sem alternância de tarefas, pois as tarefas realizadas no teste espelham a ordem realizada fora do teste. Foram colhidos dados quantitativos de tempo e número de erros, e qualitativos, dos comentários dos participantes durante o teste e no questionário pós-teste.

\subsection{Descrição da revista}

BurdaStyle é uma revista de moda que contém pequenas coleções de roupas com moldes para sua confecção. No meio da revista, há um encarte em papel jornal, impresso em preto e branco, que aqui será chamado de caderno de moldes. A primeira página desse caderno contém instruções para uso dos moldes da revista.

Em seguida, uma página com desenho e referência d os modelos da edição, identificados por números. Na página seguinte, uma tabela de medidas e instruções sobre como medir o seu corpo. A próxima parte do caderno contém as informações de cada modelo: tamanhos, materiais para confecção, plano de corte, instruções para costura, e outros (ver Figura 3).

No meio do caderno de moldes, está grampeado um encarte, também em papel jornal, com quatro folhas de molde. As folhas de molde são identificadas por letras (A, B, C e D). Cada uma contém o traçado de vários moldes, em quatro cores diferentes. Devido à quantidade de moldes por folha, os traçados ficam sobrepostos (ver Figura 4).

No momento da realização dos testes, a edição brasileira da revista ainda não estava disponível, portanto a versão portuguesa foi usada.

\subsection{Participantes e recrutamento}

Para testar a usabilidade da revista para iniciantes, foram selecionados apenas participantes sem experiência em costura e modelagem. A amostra de 12 participantes foi recrutada por conveniência, e todos responderam o questionário de seleção. 


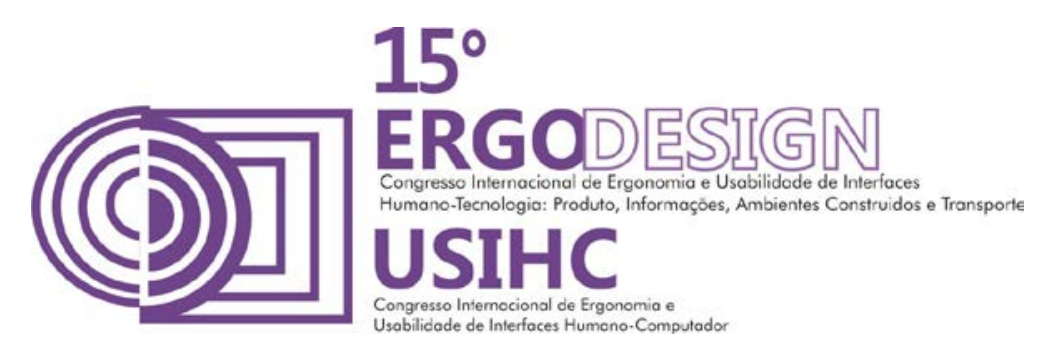

Dados coletados dos participantes foram a área profissional, a faixa etária e o grau de instrução. Esta última foi usada para comparação de resultados, portanto foram selecionados 6 participantes com ensino médio e 6 participantes com ensino superior. Todos os participantes tinham idade entre 20 e 60 anos.

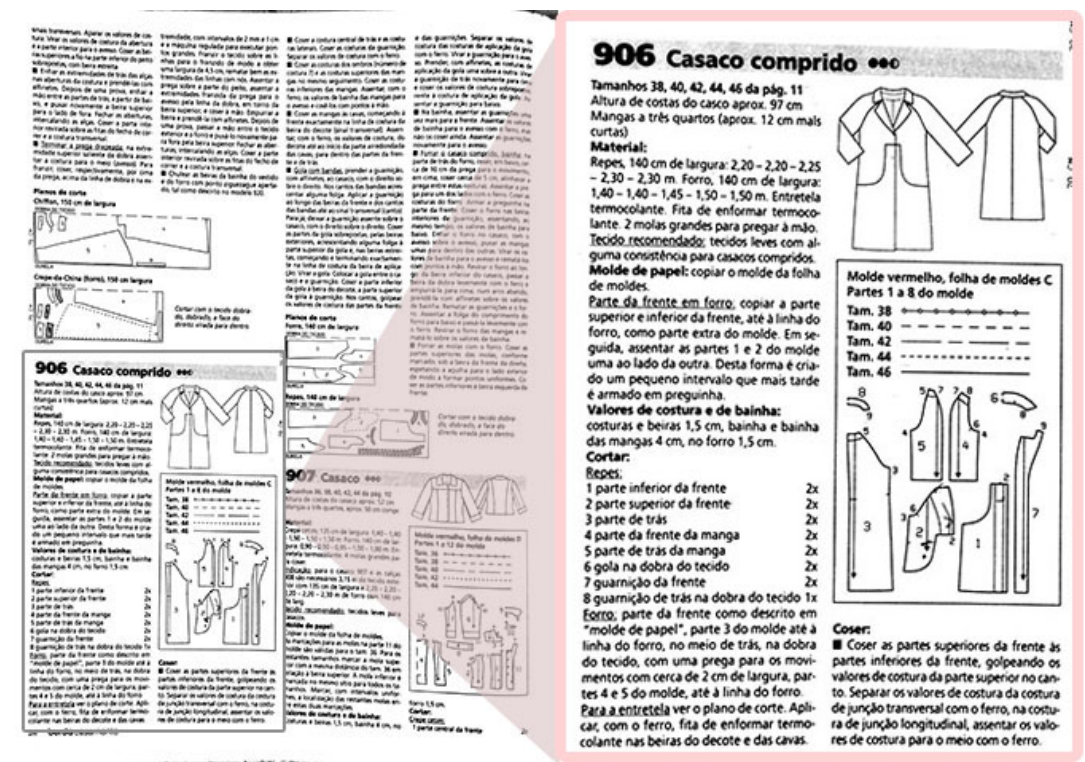

Figura 3: Página em que se encontram as informações do modelo $n^{\circ} 906$ com recorte ampliado à direita. Fonte: BURDASTYLE, 2011.

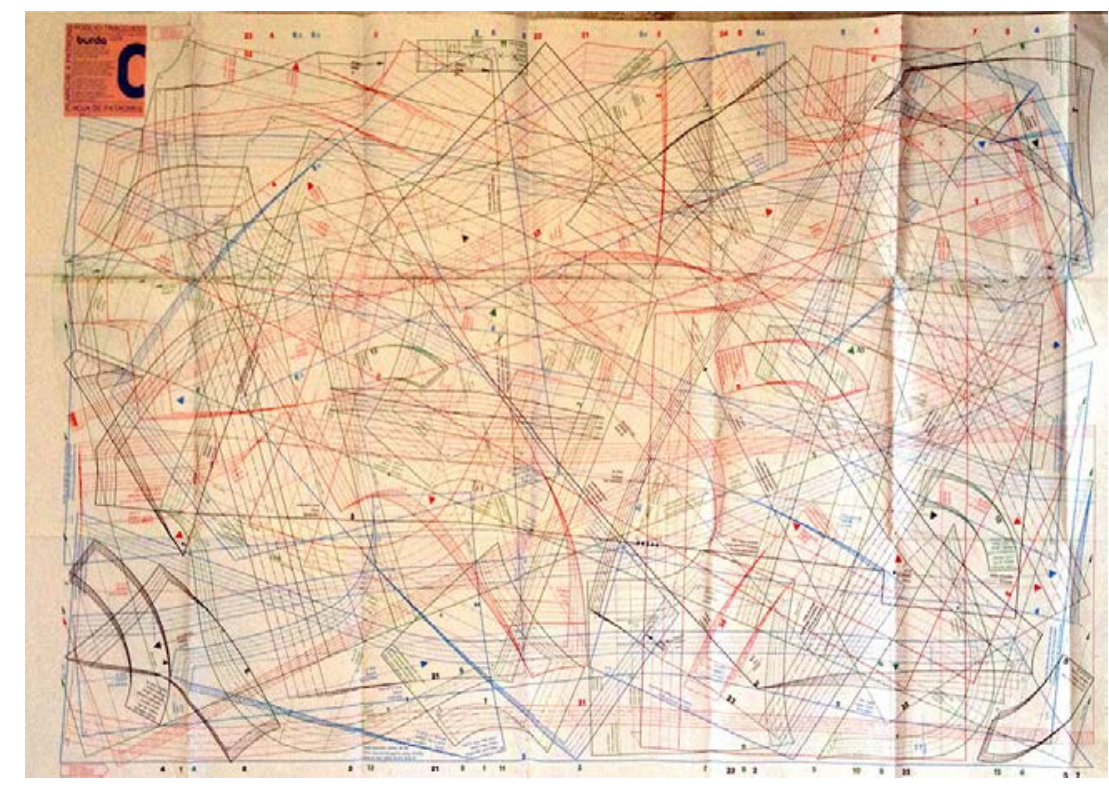

Figura 4: Folha de moldes C. BURDASTYLE, 2011. 


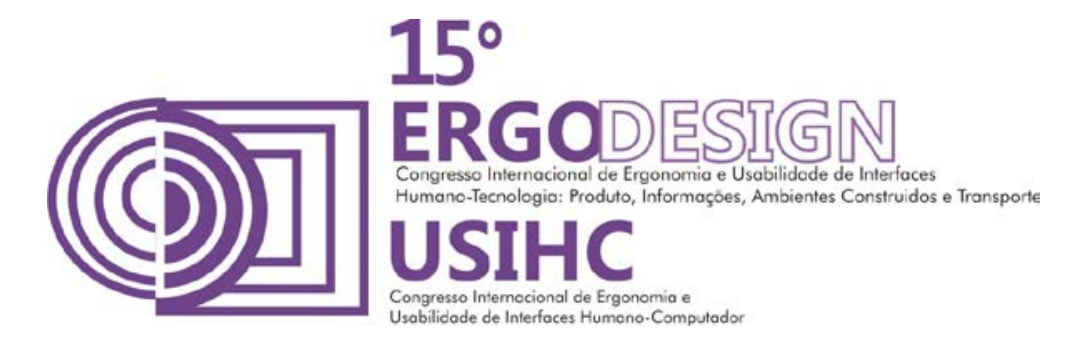

Tabela 1: Perfil dos participantes

\begin{tabular}{|l|l|l|l|}
\hline & Área & Grau de instrução & Faixa etária \\
\hline Part. 1 & Teatro & Médio & $21-40$ \\
\hline Part. 2 & Escrita & Médio & $21-40$ \\
\hline Part. 3 & Direito & Superior & $41-60$ \\
\hline Part. 4 & Artes Plásticas & Superior & $41-60$ \\
\cline { 2 - 4 } Part. 5 & Nutrição & Médio & $21-40$ \\
\hline Part. 6 & Design gráfico & Médio & $21-40$ \\
\hline Part. 7 & Teatro & Superior & $21-40$ \\
\hline Part. 8 & Design gráfico & Superior & $21-40$ \\
\hline Part. 9 & História & Superior & $21-40$ \\
\hline Part. 10 & Não informado & Médio & $21-40$ \\
\hline Part. 11 & Design & Médio & $21-40$ \\
\hline Part. 12 & Administração & Superior & $21-40$ \\
\hline
\end{tabular}

\subsection{Laboratório e equipamentos}

O testes foram realizados em 12 sessões de aproximadamente 45 minutos cada, distribuídas em 3 dias. O Laboratório de Formas do Centro de Artes da UDESC foi cedido para esse propósito. Esse laboratório contém mesas grandes e altas que permitem o trabalho tanto de pé quanto sentado. Ao lado da mesa, em um tripé, foi instalada uma câmera para gravar os testes.

Foram disponibilizados para os participantes: uma cópia da revista BurdaStyle 2/2012, folhas de papel seda, lápis 6B, apontador e borracha, papel de rascunho, pesos de papel, e réguas de modelagem. 


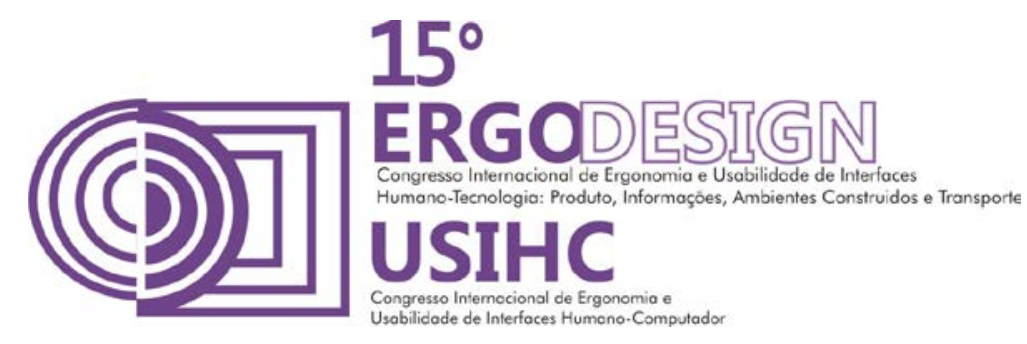

\subsection{Teste piloto}

Foram realizados dois testes piloto, em que foram anotadas algumas modificações para melhorar os próximos testes e reduzir ambiguidades nos textos.

\subsection{Teste em laboratório com participantes}

$\mathrm{Na}$ chegada dos participantes na sala, estes leram e assinaram o Termo de Consentimento Livre e Esclarecido (TCLE) e de permissão do uso da imagem. Em seguida, a câmera foi ligada e o moderador leu o roteiro de teste, explicando o que é a revista BurdaStyle e o que é um teste de usabilidade. O moderador reforçou que sua participação não era obrigatória e o participante poderia desistir a qualquer momento. Os participantes foram instruídos a "pensar em voz alta".

O moderador leu o cenário de teste, que dá um contexto para o participante realizar as tarefas. Esse contexto era que o participante gostaria de costurar uma calça que lhe servisse melhor, portanto resolveu usar os moldes da revista. A lista de tarefas foi entregue aos participantes, que só poderiam ler a segunda tarefa depois de ler a primeira, e assim por diante.

A primeira tarefa pedia ao participante que anotasse quantos metros de tecido seriam necessários para costurar o modelo $\mathrm{n}^{0}$ 906. Os participantes tiveram que encontrar essa informação no corpo do texto do caderno de moldes. A segunda tarefa pedia que encontrassem, na folha de moldes, o molde $n^{\circ} 2$ do modelo já citado, e que o indicassem com as mãos. Na terceira tarefa, os participantes deveriam copier, com papel seda, esse molde no tamanho 42 e todas as suas informações, que são essenciais para o corte da peça.

Durante as tarefas, os participantes puderam fazer perguntas. Quando eles ficavam confusos e percebia-se que não conseguiriam encontrar a informação por conta própria, o moderador interferia para ajudá-los. Foram anotadas todas as vezes em que um participante recebeu ajuda, e ainda se esse completou a tarefa corretamente, o número de erros, número de vezes que visitou a introdução do caderno de moldes, comentários e perguntas. A gravação em vídeo serviu para conferir os dados.

Após terminar as três tarefas, os participantes preencheram o questionário pós-teste, em que puderam avaliar a sua dificuldade e se julgaram ter realizado as tarefas de forma satisfatória. Responderam se acharam o material de suporte da revista suficiente para realizar as tarefas e se as mesmas são simples. Ainda tiveram espaço para comentar suas dificuldades e dar sugestões para a revista.

\subsection{Tratamento dos dados}

Foi calculada a porcentagem de participantes que conseguiu completar as tarefas sem erros e número de vezes em que o participante recebeu ajuda do moderador. Ainda foram calculadas as porcentagens de participantes que copiaram os moldes corretos, mas com erros (tarefa 3). Foram considerados erros: a omissão de elementos e o excesso de elementos.

Os comentários foram agrupados por tarefas e analisados com relação ao seu conteúdo. Ainda foram extraídas informações quantitativas destes comentários, como o número de apreciações negativas e o número de vezes em que os participantes fizeram uma pergunta específica. 


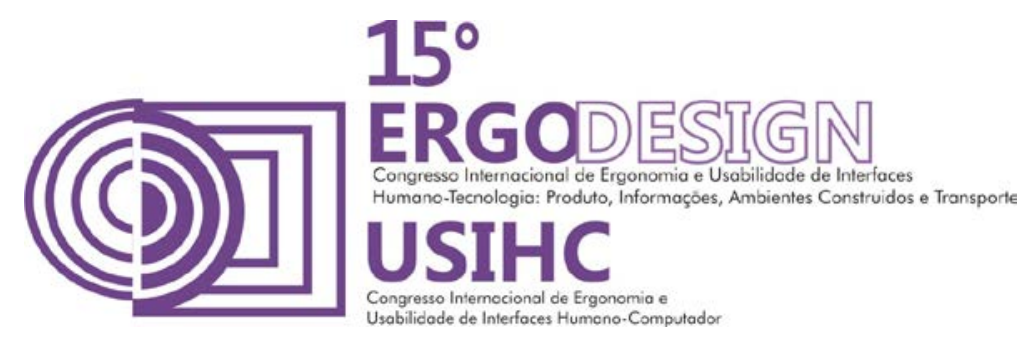

As respostas dos questionários pós-teste foram quantificadas e os comentários por escrito foram agrupados. As palavras-chave de cada comentário foram destacadas para evidenciar os temas e facilitar a análise.

\section{RESULTADOS}

Todos os participantes apresentaram alguma dificuldade para realizar as tarefas. Os resultados do teste estão detalhados por tarefa.

\subsection{Localizar a quantidade de tecido necessária}

A primeira tarefa (localizer quantidade de tecido necessária, ver Figura 5), foi completada por 5 dos 12 participantes, e sem assistência por apenas 1.

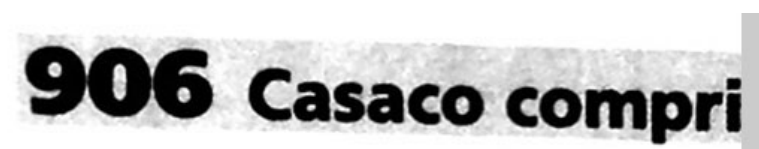

Tamanhos 38, 40, 42, 44, 46 da pág. 11 Altura de costas do casco aprox. $97 \mathrm{~cm}$ Mangas a três quartos (aprox. $12 \mathrm{~cm}$ mais curtas)

Material:

Repes, $140 \mathrm{~cm}$ de largura: $2,20-2,20-2,25$ - 2,30 - 2,30 m. Forro, $140 \mathrm{~cm}$ de largura: 1,40 - 1,40 - 1,45 - 1,50-1,50 m. Entretela termocolante. Fita de enformar termocolante. 2 molas grandes para pregar à mão. Tecido recomendado: tecidos leves com alguma consistência para casacos compridos.

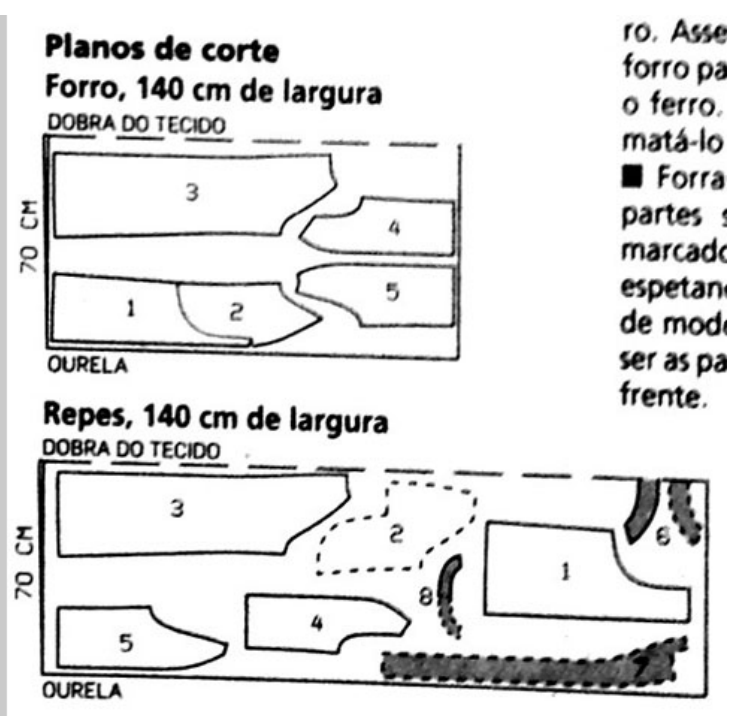

Asse

o ferro.

mata-lo

marcadc

espetan

de modi

ser as pa

Repes, $140 \mathrm{~cm}$ de largura

DOBRA DO TECIDO

Figura 5: Quantidade de tecido necessária (à esquerda) e planos de corte (à direita). Fonte: BURDASTYLE, 2011.

$58.3 \%$ dos participantes perguntaram o que era "repes", nome do tecido indicado pela revista. $\mathrm{Na}$ seção "Materiais", onde deveria ser encontrada a informação necessária para esta tarefa, era sugerido o "repes", mas em nenhum lugar da seção foi indicado que esse era um tecido.

Outra barreira para realização desta tarefa foi a medida de largura do rolo do tecido, $140 \mathrm{~cm}$. Os participantes não sabiam que era uma largura padrão, e alguns achavam que teriam que calcular a quantidade de tecido em metros quadrados.

Dois dos participantes confundiram-se com o desenho do plano de corte (ver Figura 6), em que os moldes estão dispostos sobre um pedaço de tecido dobrado. Junto a ele, é indicada a largura de $140 \mathrm{~cm}$, o que pode sugerir que essa seja a quantidade de tecido necessária para a peça. A quantidade correta não está escrita perto do plano de corte. 


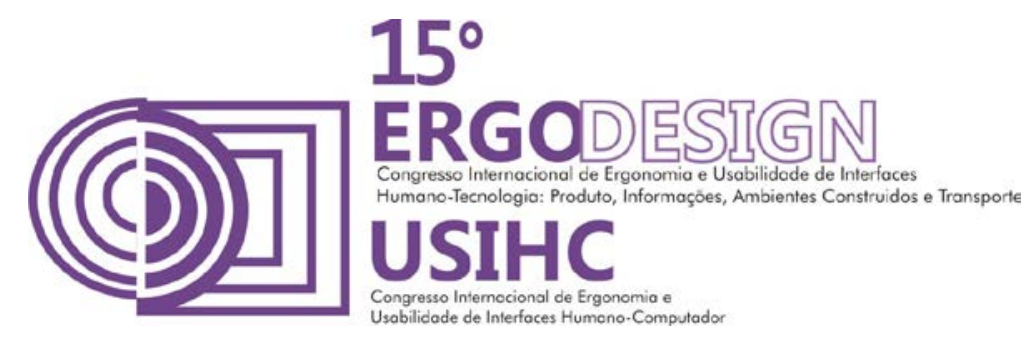

Outra causa de erro identificada com ajuda dos comentários foi que as medidas de tecido são apresentadas na mesma sequência dos tamanhos, por exemplo: 2,20 - 2,20 - 2,25 - 2,30 2,30. A sequência de tamanhos, que é "38, 40, 42, 44 e 46", está indicada em um parágrafo anterior às medidas de tecido, e portanto a ligação entre eles não é clara. (Ver Figura 5).

\subsection{Localizar um molde}

A segunda tarefa (localizar um molde na folha de moldes), foi completada com sucesso por 8 dos participantes, 4 sem assistência. Esta foi a tarefa com mais alta taxa de sucesso.

Os comentários indicaram que $50 \%$ dos participantes tiveram dificuldade de encontrar os números distribuídos na folha de moldes, e que servem para localizar o molde correto (ver Figura 6). Em uma mesma folha de moldes há números que se repetem, mas são de cores diferentes e modelos diferentes. Ao procurar o número do molde, os participantes se confundiram.
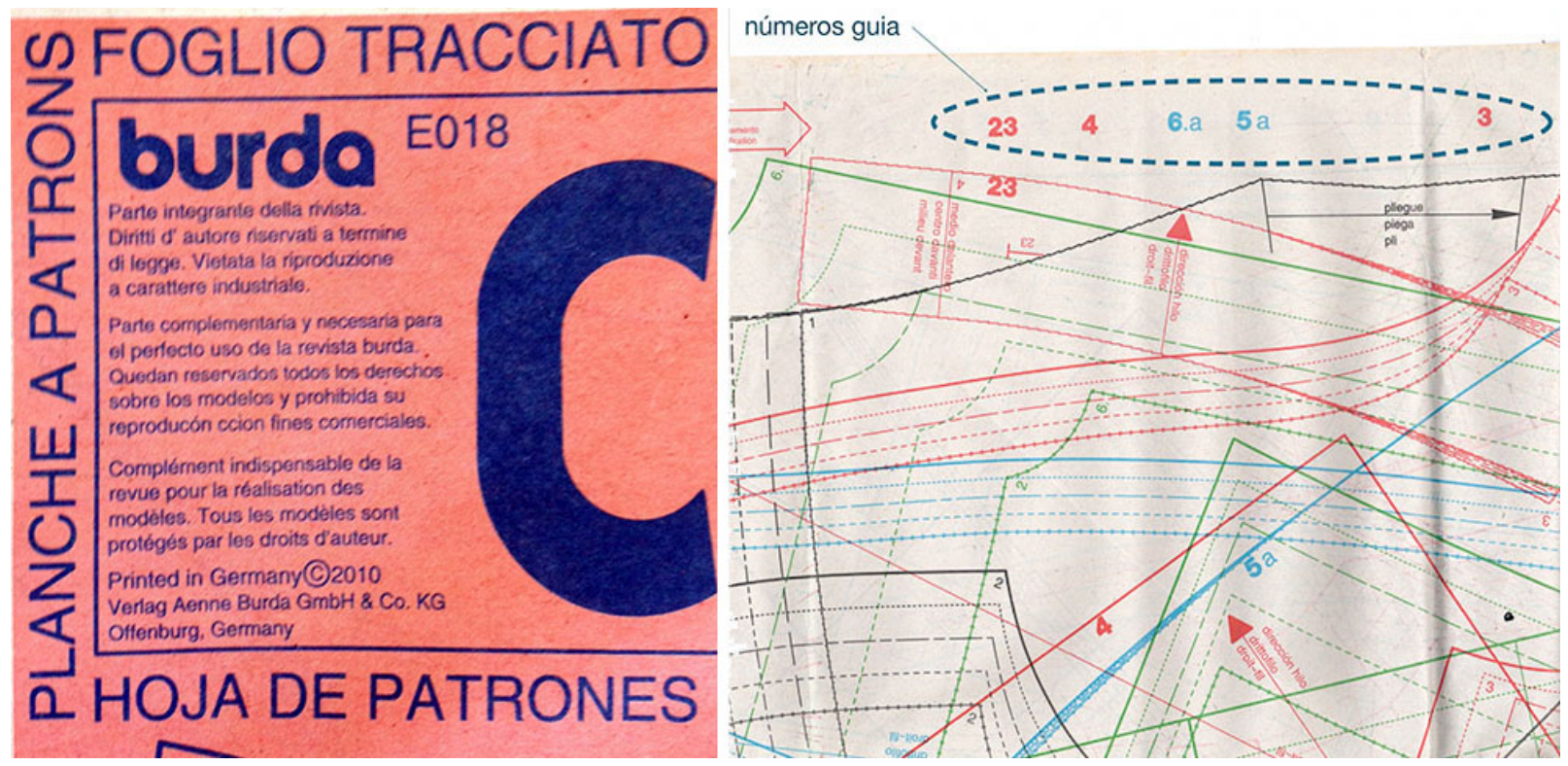

Figura 6: Legenda da folha de moldes C (à esquerda) e números guia indicados por circunferência

(à direita). Fonte: modificada de BURDASTYLE, 2011.

Outro problema que os participantes tiveram com os números foi que tanto o modelo quanto o molde são representados por códigos numéricos independentes. O número do modelo não está evidente na folha de moldes, e não aparece na guia das margens. A mesma, que serve para facilitar a localização dos números dos moldes, não está suficientemente destacada (ver Figura 6). Além disso, a legenda da folha de moldes (ver Figura 7), um quadro no canto superior esquerdo que identifica a folha e a edição da revista, não diz quais modelos estão representados naquela folha. 


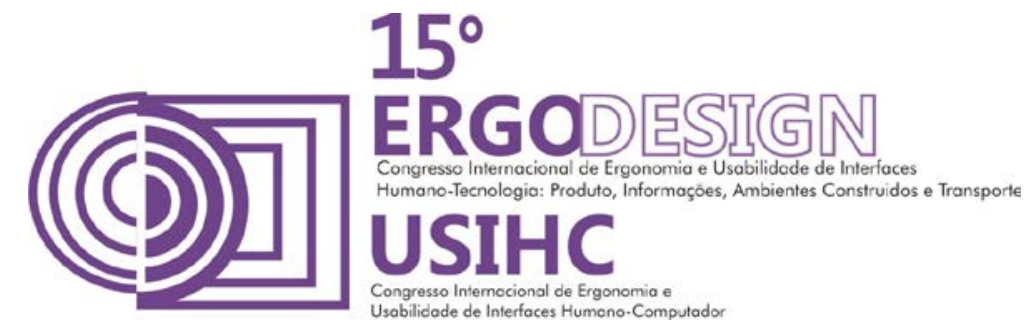

Uma dificuldade frequente entre os participantes foi descobrir em qual folha de moldes estaria o molde que estavam procurando. Essa informação está inclusa em um pequeno quadro na revista, mesmo quadro que mostra o traçado do molde em miniatura (ver Figura 7).

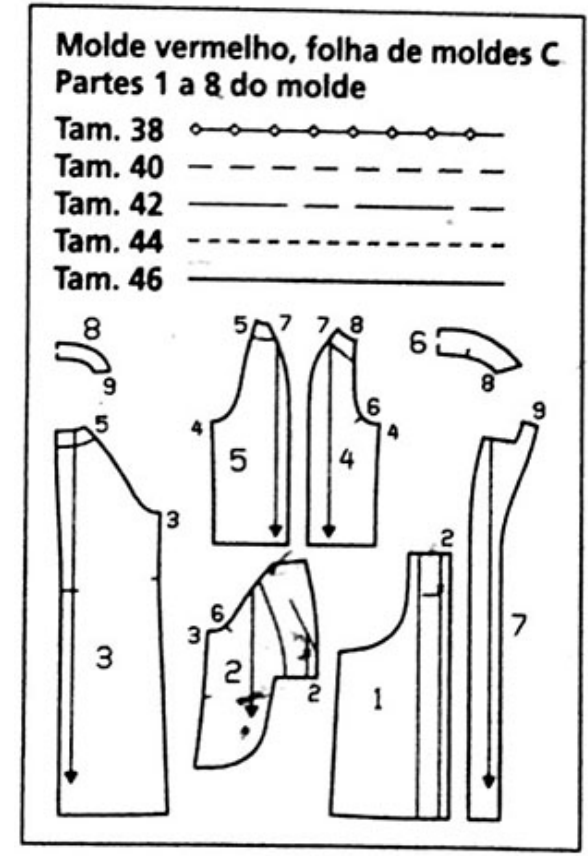

Figura 7: Quadro com miniatura dos moldes e localização dos mesmos na folha de moldes. Fonte: BURDASTYLE, 2011.

\subsection{Copiar um molde}

Os participantes tiveram maior dificuldade na atividade de copiar o molde com todas as informações, e apenas 3 concluíram corretamente, 1 deles sem assistência.

Dentre os participantes que copiaram o molde indicado, 80\% faltaram com alguma informação, e $20 \%$ copiaram alguma marcação a mais, que não pertencia ao molde indicado.

Os comentários sugeriram que esta foi uma tarefa difícil e confusa, e alguns deles estão apresentados na tabela 2. Com base nos resultados quantitativos e nos comentários dos participantes, fica claro que a maior barreira para o sucesso desta tarefa é encontrar as informações pertencentes ao molde, como piques, linha de direção do fio e botões. Não fica evidente ao usuário quais marcações fazem parte do molde, pois há vários sobrepostos, algumas vezes da mesma cor (ver Figura 4). 


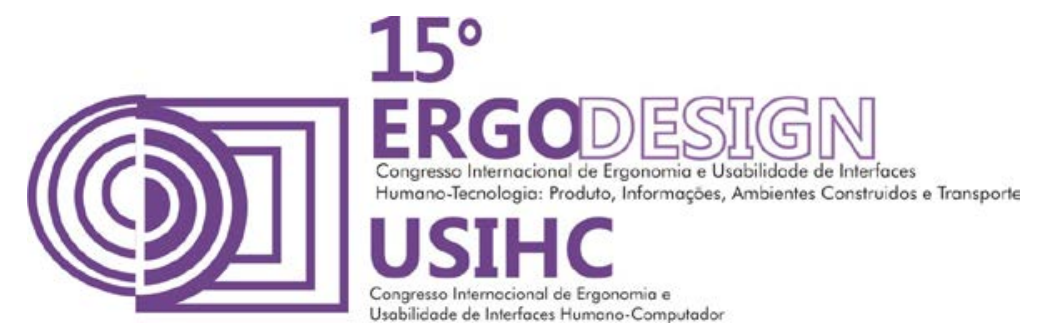

Tabela 2: Alguns dos comentários feitos pelos participantes durante a Tarefa 3.

"Estou tentando entender se essa linha que estou seguindo é a linha do tamanho 42."

"Não estou achando uns riscos que deveriam estar..."

"Estou meio perdido."

"Estou com dificuldade de encontrar essas informações."

"Achei meio confuso."

"Suponho que o que esteja dentro do desenho do molde seja pertinente a ele."

"São muitos símbolos e muitos moldes, o que dificulta o entendimento."

"Eu tenho essas informações em algum lugar?"

O quadro de moldes da revista, que apresenta miniaturas do traçado e poderia facilitar a identificação dessas marcações (ver Figura 10), demorou a ser identificado pelos participantes, que precisaram da ajuda do moderador.

Os participantes não sabiam que havia uma folha de instruções na revista, e nas suas atividades não encontraram nenhuma indicação de que ela existia. Neste aspecto, também houve falha dos moderadores, que colocaram as folhas de moldes da revista dobradas exatamente no centro da mesma, que é a sua posição original. Isso, e o fato de que as informações do modelo $\mathrm{n}^{\circ} 906$ estavam próximas ao centro, pode ter influenciado os participantes a folhearem apenas as páginas centrais da revista.

Por último, há muitos moldes sobrepostos, de traçados de espessuras parecidas e algumas vezes cores iguais. Os participantes comentaram que é difícil acompanhar o desenho do molde e diferenciar um molde do outro, principalmente no caso das marcações.

A diferença entre os resultados de participantes com ensino médio e de participantes com ensino superior não foi significativa. Dentre os seis participantes com ensino médio, em média 2,6 partipantes completaram as tarefas com sucesso. Dentre os seis com ensino superior, a média foi de 3 participantes.

\section{RECOMENDAÇÕES}

No questionário pós-teste, alguns participantes sugeriram um glossário de termos e símbolos, e um passo a passo geral de como usar o caderno e a folha de moldes. Os participantes também sugeriram variar mais a espessura de traços do caderno de moldes e diminuir a quantidade de elementos por folha. 


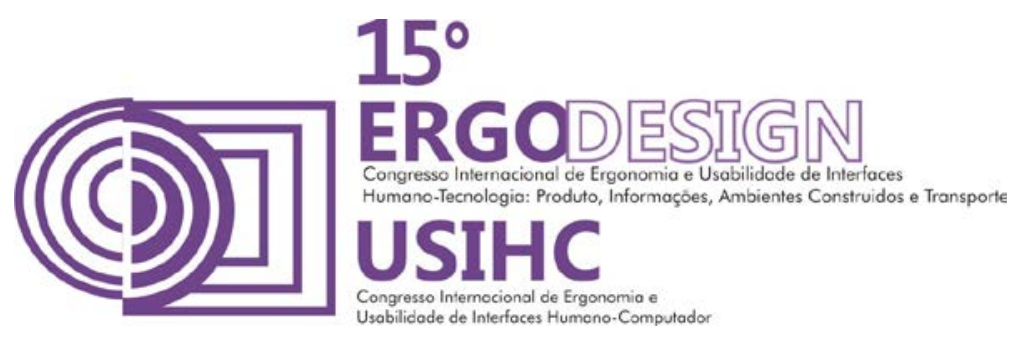

Baseadas nos comentários dos participantes, outras modificações podem ser sugeridas. Para o caderno de moldes, identificar os tecidos como tal, e enunciar de forma clara quais materiais são necessários e sua quantidade. Durante a atividade em que deveriam anotar a quantidade de tecido necessária para costurar, a pergunta "o que é repes?" foi feita sete vezes. O texto em geral pode ser escrito de forma mais clara e explicativa, com fonte e espaçamento maiores, como sugerem os comentários dos Participante 3, 12 e 6, respectivamente: "pelo fato de eu nunca ter costurado, considero as informações da revista muito técnicas para uma "leiga"; "colocar um passo a passo geral na revista, de como encontrar os moldes, informações e calcular o tamanho" e "muita dificuldade em encontrar as informações de instrução e na folha de cortes. Muita informação disposta no mesmo local".

A adição de infográficos foi sugerido por um dos participantes. Segundo Caixeta (2005 apud MÓDOLO, 2007), o infográfico "É uma forma de representar informações técnicas como números, mecanismos e/ou estatísticas, que devem ser sobretudo atrativos e transmitidos ao leitor em pouco tempo e espaço".

O plano de corte poderia ser apresentado com as medidas de tecido necessárias para a confecção do modelo, além da largura do tecido, e assim ficaria mais claro aos usuários quais as medidas necessárias para a confecção. Esta recomendação é sugerida a partir dos resultados da primeira tarefa.

No caderno de moldes, seria interessante deixar a guia das margens em evidência e usar o número do modelo junto ao número do molde. Essa foi uma sugestão do Participante 9: "A indicação de cada molde $(1,2,3,4 \ldots)$ podia ser mais aparente". O número dos modelos contidos na folha também poderia ser indicado na legenda da mesma, assim o usuário tem outras maneiras de localizar a folha correta. A legenda poderia trazer uma indicação de que existem instruções na revista e a página em que se encontram, como sugerido pelo comentário do Participante 3: "Colocar um aviso no encarte catálogo de moldes para informar em qual página da revista estão as instruções para utilizar e fazer o molde".

A modificação mais crítica, contudo, é a redução da quantidade de moldes por folha, já que 12 dos comentários feitos pelos participantes durante a tarefa de copiar o molde fazem referência à quantidade de linhas sobrepostas.

\section{DISCUSSÃO}

Em geral, as dificuldades mais comentadas pelos participantes no questionário pós-teste são a falta de informação clara e a grande quantidade de elementos visuais. A maioria dos participantes sentiu que Ihes faltava conhecimento para realizar as tarefas, e alguns sugeriram que com mais experiência, ou em uma segunda tentativa, teriam mais facilidade. Isso indica que com uma linguagem mais clara e menos especializada, a revista poderia ser usada mais facilmente pelos iniciantes.

Neste teste, testamos a usabilidade apenas no primeiro contato do usuário, portanto a validade dos resultados não se estende ao uso contínuo ou com experiência do produto. Como citado anteriormente, alguns participantes acharam que teriam melhores resultados nos próximos usos da revista. 


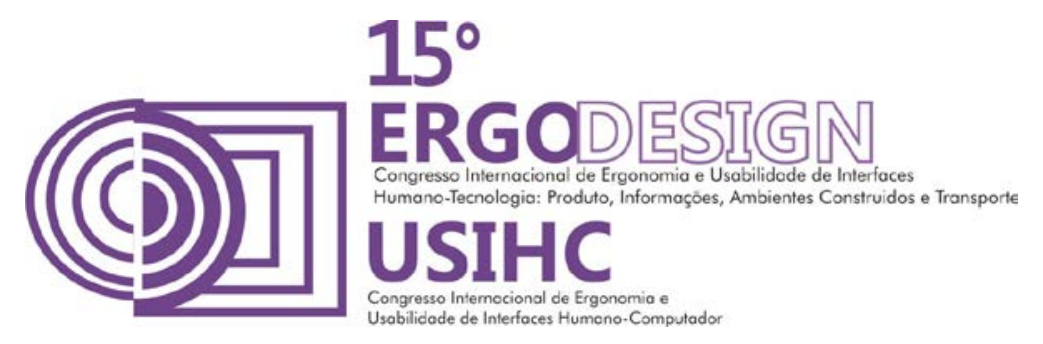

O outro problema frequente dos participantes foi encontrar a informação necessária no meio de muitos traçados ou mesmo no meio de muito texto, já que a fonte e o espaçamento do texto do caderno de moldes são muito pequenos. Os resultados do teste sugerem que a usabilidade da revista melhoraria se corrigissem esses problemas, e tornaria-se mais fácil de usar por iniciantes. Consequentemente, isso melhoraria a usabilidade para os usuários em geral. Outra consequência importante dessa melhoria seria a utilização mais eficiente de tempo e recursos materiais, que acabam sendo desperdiçados devido ao volume de erros.

Ao abrir a folha de moldes no teste, a maioria dos participantes mostrava surpresa com a complexidade de informação. É possível que essa impressão inicial prejudique as chances de o iniciante levar a tarefa à frente, o que se torna um grande obstáculo a possibilitar o uso para um maior número de pessoas. Um dos participantes, enquanto copiava o molde, comentou que se estivesse tentando fazer isso sozinho, já teria desistido.

O teste não mediu a usabilidade das instruções de costura da revista, nem da tabela de medidas. A avaliação da página de instruções não foi significante, por ela não ter sido usada com frequência pelos participantes do teste, como comentado nos resultados da tarefa 3.

Pesquisas futuras poderiam ser realizadas com usuários com experiência em costura, ou usuários iniciantes com as novas seções para iniciantes da revista. Outras revistas de moldes de costura também poderiam ser testadas, já que apresentam configurações diferentes.

\section{REFERÊNCIAS BIBLIOGRÁFICAS}

BURDA COMMUNITY NETWORK. 2013/2014 BurdaStyle US media kit. Disponível em: < http://bcn.burda.com/Service/Download-Center/download?downloadDocument=971d9960-0eeb-fb727845-c09834894041>. Acesso em 28 de ago. de 2014.

ABNT NBR ISO 9241-210:2011, Ergonomia da interação humano-sistema. Parte 210: Projeto centrado no ser humano para sistemas interativos.

DEUTSCHE WELLE. Aenne Burda, famosa pela revista com modelos de costura, faria 100 anos, jul. de 2009. Disponível em: <http://www.dw.de/aenne-burda-famosa-pela-revista-com-modelos-de-costurafaria-100-anos/a-4523563>. Acesso em 28 de ago. de 2014.

BURDASTYLE. Lisboa: TailorMade, fevereiro de 2011.

CHISNELL, D. RUBIN, J. Handbook of Usability Testing: how to plan, design and conduct effective tests. 2ed. Indianapolis: Wiley Publishing, 2008.

EDITORA ABRIL. Manequim mídia kit 2014. Disponível em: < http://publiabril.abril.com.br/marcas/34/download-media-kit>. Acesso em 28 de ago. de 2014.

KIDWELL, C. B. Cutting a fashionable fit: dressmakers' drafting systems in the United States. Washington: Smithsonian Institution, 1979.

MÓDOLO, C. M. Infográficos: características, conceitos e princípios básicos. In. XII Congresso Brasileiro de Ciências da Comunicação da Região Sudeste, Juiz de Fora. 2007.

NEMETH, C. P. Human factors methods for design: making systems human-centered. London: CRC, 2004. 